\title{
Effects of Calcium and Aluminum on Particle Settling in an Oil Sands End Pit Lake
}

\author{
Kai Wei ${ }^{1} \cdot$ Heidi L. Cossey ${ }^{1} \cdot$ Ania C. Ulrich ${ }^{1,2}$ (D)
}

Received: 27 October 2020 / Accepted: 28 July 2021 / Published online: 7 August 2021

(c) The Author(s) 2021

\begin{abstract}
Surface mining of oil sands ore in Alberta, Canada has generated fluid fine tailings (FFT) that must be reclaimed. End pit lakes (EPLs), which consist of thick deposits of FFT capped with water, have been proposed for FFT reclamation, and Base Mine Lake (BML) is the first full-scale demonstration EPL. However, FFT particle settling and resuspension contributes to high turbidity in the BML water cap, which may be detrimental to the development of an aquatic ecosystem. This study investigated the effect of $\mathrm{Ca}$ and $\mathrm{Al}$ treatments on turbidity mitigation. The initial turbidity was reduced from 20 NTU to less than $2 \mathrm{NTU}$ in BML surface water treated with $54 \mathrm{mg} / \mathrm{L}$ of $\mathrm{Ca}$ or $1.1 \mathrm{mg} / \mathrm{L}$ of Al. At a concentration of $1.1 \mathrm{mg} / \mathrm{L}, \mathrm{Al}$ reduced the initial turbidity to a greater extent, and in a shorter time, than $54 \mathrm{mg} / \mathrm{L}$ of Ca. Further, resuspended Al-treated FFT particles were 100-700 nm larger in diameter, and thus resettled faster than the resuspended untreated or Ca-treated FFT particles. The final turbidity values 21 days after resuspension of untreated and $1.7 \mathrm{mg} / \mathrm{L}$ Al-treated FFT particles in fresh BML surface water were $20.5 \mathrm{NTU}$ and $2.5 \mathrm{NTU}$, respectively. Thus, Al treatment may be effective in mitigating turbidity in BML through both Al-induced coagulation and self-weight settling of the resuspended Al-treated FFT particles.
\end{abstract}

Keywords Tailings $\cdot$ Coagulation · Turbidity $\cdot$ Base Mine Lake

\section{Introduction}

Bitumen extraction from surface-mined oil sands ore in Alberta, Canada generates large volumes of waste (tailings) made up of solids, residual bitumen, and oil sands processaffected water (OSPW). Fluid fine tailings (FFT) consist of fine clay and silt particles $(<44 \mu \mathrm{m})$. These tailings are particularly problematic because they form a stable colloidal suspension that can take decades to naturally dewater and consolidate (Kasperski and Mikula 2011; Syncrude Canada Ltd. 2019). Over 1.25 billion $\mathrm{m}^{3}$ of FFT are slowly settling and consolidating in above-ground impoundments referred to as tailing ponds (AER 2019). Oil sands operators are currently investigating alternative strategies for managing

Ania C. Ulrich

aulrich@ualberta.ca

1 Department of Civil \& Environmental Engineering, University of Alberta, Alberta T6G 1H9 Edmonton, Canada

2 Department of Civil \& Environmental Engineering, University of Alberta, Rm. 7-265 Donadeo Innovation Center for Engineering (ICE) Building, 9211-116th St NW, Alberta, Edmonton, Canada and reclaiming these tailings, one of which is end pit lakes (EPLs). EPLs are thick deposits of FFT capped with water in decommissioned open pits. The water cap (hereafter referred to as surface water) provides habitat for an aquatic ecosystem while the FFT is allowed to naturally dewater and consolidate over time (Charette et al. 2010). EPLs are expected to develop into functional components of mine closure landscapes. However, EPLs are subject to demonstration, assessment, and research before the Alberta Energy Regulator (AER) approves this tailings reclamation technology (AER 2019).

Base Mine Lake (BML), commissioned in 2012 and operated by Syncrude Canada Ltd., is the first full-scale demonstration EPL in the Alberta oil sands. At the time of commissioning, BML consisted of $45 \mathrm{~m}$ of FFT covered with 5-10 m of water, with an area $>800$ ha. BML is continuously being monitored to determine if EPLs are a feasible FFT management and reclamation option. Field data shows that surface water turbidity in BML increases after lake turnover and can reach as high as 308 NTU (Tedford et al. 2019). Lawrence et al. (2016) identified numerous processes conceivably affecting the vertical mixing of suspended solids in BML including wind waves, convection 
due to salt-water exclusion during ice formation, penetrative convection due to surface cooling, gas ebullition, and internal wave activity. These processes can resuspend settled particles and thus increase the turbidity. In addition to vertical transport, shoreline erosion may also contribute to the inventory of suspended solids in BML. High surface water turbidity could adversely affect ecological development and thereby the success of this reclamation technology. For a healthy littoral zone to develop, sunlight should penetrate the surface water cap to a depth of at least 2-3 m (Charette et al. 2010). The littoral zone is expected to support the highest biodiversity in the lake and to help regulate dissolved oxygen and provide food for fish and wildlife (Charette et al. 2010).

Suspended clay particles that contribute to the high turbidity in BML have negative surface charges that lead to the formation of a diffuse double layer, repel other particles, and hinder the particle settling process (Schofield and Samson 1954; Sutherland et al. 2015). Schulze (1882) and Hardy (1900) recognized that salts containing multivalent ions are much more efficient in suppressing the repulsion between clay particles and coagulating colloidal suspensions than salts containing monovalent ions. As such, wastewater treatment and drinking water treatment commonly employ multivalent cations such as calcium sulfate, aluminum sulfate, and ferric chloride as coagulation/flocculation agents that aid in the settling of fine particles (White et al. 2011). Chemicals with multivalent cations have also been studied and used in the oil sands industry to enhance FFT dewatering. Sworska et al. (2000) found that the polymer polyacrylamide was not effective in destabilizing dispersed particles at the alkaline $\mathrm{pH}$ of FFT, but the presence of divalent magnesium and calcium ions dramatically improved the clarity of the supernatant of fine tailings in an alkaline environment. Long et al. (2006) similarly observed that both $\mathrm{Ca}$ and $\mathrm{Mg}$ ions induced adhesion between fine particles and proposed an oil sands tailings treatment technology based on a combination of partially hydrolyzed polyacrylamide and divalent ions. Alum, containing the trivalent cation $\mathrm{Al}$, has also been assessed as a useful coagulation aid in the composite tailings process for tailings treatment, wherein FFT, coarse material, and a coagulant are combined to rapidly dewater the FFT (Matthews et al. 2002).

Based on this previous research, $\mathrm{Ca}$ and $\mathrm{Al}$ were selected as candidate coagulants to mitigate turbidity in BML surface water. Calcium and $\mathrm{Al}$ are abundantly available at oil sands mining operations and are relatively inexpensive. So, we compared the effectiveness of $\mathrm{Ca}$ and $\mathrm{Al}$ in reducing initial turbidity in BML surface water using bottle coagulation tests. Furthermore, since there were no studies that determined the long-term efficacy of coagulants in reducing additional turbidity introduced in the years following initial turbidity removal, we used a laboratory-based approach to investigate the prolonged effects of coagulant addition. This study is the first to investigate how coagulant-treated BML surface water and coagulant-treated particles affect turbidity caused by resuspension of FFT particles in BML surface water using a series of resuspension tests. The results from this study are critical in determining an effective coagulant for BML and the operational costs of coagulant application to BML. This work will help mitigate turbidity issues that may be detrimental to the development of aquatic ecosystems in EPLs.

\section{Materials and Methods}

\section{Sample Collection and Characterization}

Grab samples of BML surface water and FFT were provided by Syncrude Canada Ltd. in Aug. 2016. BML surface water samples were collected from the top $2 \mathrm{~m}$ of BML and FFT was sampled at a depth of $10.2 \mathrm{~m}$ below the lake surface ( $1.0 \mathrm{~m}$ below the surface water-FFT interface). This FFT sampling depth was chosen because particles near the surface water-FFT interface are more likely to be resuspended than deeper deposited particles. The FFT particles used in this work were characterized for particle size distribution following the procedure described in ASTM International D79828-17: standard test method for particle-size distribution (gradation) of fine-grained soils using the sedimentation (hydrometer) analysis (2017) and using a $152 \mathrm{H}$ hydrometer (Fisherbrand). BML surface water was analyzed for $\mathrm{pH}$, electrical conductivity (EC), alkalinity, major cations, major anions, dissolved organic carbon (DOC), and acidextractible organics (AEOs). The $\mathrm{pH}$ was measured using an Accumet AR50 dual-channel meter (Fisher Scientific, Lenexa, Kansas) and EC was measured using an ExStik II Meter (Extech, Nashua, New Hampshire). Alkalinity was determined using a Mettler Toledo DL53 Titrator (Mississauga, Canada) with $0.02 \mathrm{~N} \mathrm{H}_{2} \mathrm{SO}_{4}$. The endpoints for carbonate alkalinity and total alkalinity were set at $\mathrm{pH} 8.3$ and $\mathrm{pH} 4.5$, respectively. Liquid samples were filtered through $0.45 \mu \mathrm{m}$ nylon filters and the filtrate was sent to the Natural Resources Analytical Laboratory (NRAL) at the University of Alberta for major cation analysis $\left(\mathrm{Na}^{+}, \mathrm{K}^{+}, \mathrm{Ca}^{2+}, \mathrm{Mg}^{2+}, \mathrm{Al}^{3+}, \mathrm{Fe}^{3+}\right)$ via inductively coupled plasma - optical emission spectrometry (ICP-OES) (Thermo iCAP 600 series, Thermo Fisher Scientific, Bremen, Germany). Major anions $\left(\mathrm{Cl}^{-}, \mathrm{SO}_{4}{ }^{2-}\right.$, $\mathrm{NO}_{3}{ }^{-}$) were analyzed using a Dionex 2000 ion chromatography system (Thermo Scientific, Bannockburn, IL) following the procedure described by Abolfazlzadehdoshanbehbazari et al. (2013). DOC was measured in filtrate (liquid samples were filtered through $0.45 \mu \mathrm{m}$ nylon filters) using a Shimadzu TOC-LCPH analyzer (Kyoto, Japan) (sparging time: $6 \mathrm{~min}$; injection volume: $50 \mu \mathrm{L}$; injection number: 3 out of 4 ; acid added: $2.3 \%$ ). AEOs were determined as 
previously described by Mahdavi et al. (2015). The turbidity was directly measured with an Orbecco-Hellige digital direct-reading turbimeter (Sarasota, Florida).

\section{Bottle Coagulation Test}

Bottle coagulation tests were conducted under quiescent conditions to understand the particle coagulation and settling behaviors during initial turbidity removal. Bottle coagulation tests were set up with $450 \mathrm{~mL}$ of BML surface water in 500 $\mathrm{mL}$ glass bottles. Calcium ions (in the form of $\mathrm{CaCl}_{2} \cdot 2 \mathrm{H}_{2} \mathrm{O}$; purchased from Sigma-Aldrich) were added to BML surface water to achieve Ca concentrations of 1.7, 3.8, 7, 29, and $54 \mathrm{mg} / \mathrm{L}$. Aluminum ions (in the form of $\mathrm{AlK}\left(\mathrm{SO}_{4}\right)_{2} \cdot 12 \mathrm{H}_{2} \mathrm{O}$; purchased from Sigma-Aldrich) were added to BML surface water to achieve $\mathrm{Al}$ concentrations of $0.6,1.1$, and $1.7 \mathrm{mg} / \mathrm{L}$. Calcium treatments of $1.7 \mathrm{mg} / \mathrm{L}$ and $3.8 \mathrm{mg} / \mathrm{L}$ were conducted because they have the same mass concentration and equivalent concentration $(0.19 \mathrm{meq} / \mathrm{L})$, respectively, as the $1.7 \mathrm{mg} / \mathrm{L}$ aluminum treatment. The other concentrations were selected based on turbidity reduction rates observed in preliminary experiments (data not shown). Coagulation was achieved by shaking the glass bottles to completely dissolve the respective chemicals in BML surface water. Glass bottles containing only untreated BML surface water were included to serve as a control. Each treatment was set up in duplicate. Turbidity and $\mathrm{pH}$ measurements were taken regularly (every three to seven days) during the experiments, which lasted 20 to 30 days. Particle size distribution and zeta potential were measured immediately (within $5 \mathrm{~min}$ ) after the addition of $\mathrm{Ca}$ and $\mathrm{Al}$ with a Zetasizer Nano ZSP (Malvern Instruments, Malvern, UK) and DTS 1070 folded capillary cells at $25^{\circ} \mathrm{C}$ through electrophoretic light scattering. The mean value for the intensity-based particle size based on cumulants analysis (the z-average size) was reported. $\mathrm{EC}$ and selected ions $\left(\mathrm{Na}^{+}, \mathrm{K}^{+}, \mathrm{Ca}^{2+}, \mathrm{Mg}^{2+}, \mathrm{Al}^{3+}, \mathrm{Cl}^{-}, \mathrm{SO}_{4}{ }^{2-}, \mathrm{HCO}_{3}{ }^{-}\right)$in $\mathrm{BML}$ surface water were analyzed at the beginning and end of the experiments to understand the changes in water chemistry. $\mathrm{HCO}_{3}{ }^{-}$concentration was calculated using measured alkalinity.

Following the bottle coagulation tests, a series of resuspension experiments were conducted and are described in the subsections below to determine the prolonged effect of adding coagulant directly to the surface water cover. The treatment conditions and purpose of each resuspension experiment are summarized in Table 1.

\section{Scenario 1: Resuspension of untreated FFT Particles in Coagulant-Treated BML Surface Water}

At the end of the bottle coagulation tests, Ca-treated, Altreated, and untreated BML surface water samples $(420 \mathrm{~mL})$ were carefully pipetted into new glass bottles. The coagulated particles that settled during the bottle coagulation test were left in the original bottles without being transferred. Untreated FFT particles (0.1-0.15 g (wet weight) per test bottle) were added to Ca-treated, Al-treated, and untreated BML surface water, and were resuspended on a shaker for $3 \mathrm{~h}$ at $160 \mathrm{rpm}$ and then allowed to settle for 20-30 days. Each treatment was set up in duplicate. Turbidity and $\mathrm{pH}$ measurements were taken regularly (every three to seven days) after resuspension. The particle size distribution and zeta potential of FFT particles were measured immediately (within $5 \mathrm{~min}$ ) after resuspension. EC and selected ions were analyzed immediately after resuspension and 22 days after resuspension. The above resuspension procedure was repeated after the introduced untreated FFT particles had coagulated and settled, once for Ca-treated bottles and twice for Al-treated bottles.

\section{Scenario 2: Resuspension of Coagulant-Treated FFT Particles in Untreated BML Surface Water}

Calcium (7, 29, and $54 \mathrm{mg} / \mathrm{L})$ and aluminum $(0.6,1.1$, and $1.7 \mathrm{mg} / \mathrm{L}$ ) were added to the suspensions of untreated FFT particles (0.1-0.15 g (wet weight)) and untreated BML surface water $(450 \mathrm{~mL})$. The lower Ca treatments of 1.7 and $3.8 \mathrm{mg} / \mathrm{L}$ were not selected for these resuspension experiments as the bottle coagulation tests indicated that turbidity reduction was not significant under these conditions. After 30 days, the resulting settled and coagulant-treated FFT particles were collected by carefully decanting BML surface water. Ca-treated, Al-treated, and untreated FFT particles were resuspended once in untreated BML surface water $(450 \mathrm{~mL})$ on a shaker for $3 \mathrm{~h}$ at $160 \mathrm{rpm}$ and allowed to settle for 20-30 days. Each treatment was set up in duplicate.

Table 1 BML FFT and BML surface water resuspension experiments

\begin{tabular}{|c|c|c|c|}
\hline & BML tailings & BML surface water & Purpose of the study \\
\hline Resuspension Scenario 1 & Untreated & Coagulant-treated & $\begin{array}{l}\text { Behavior of residual coagulant in BML surface water } \\
\text { following the initial treatment }\end{array}$ \\
\hline Resuspension Scenario 2 & Coagulant-treated & Untreated & Behavior of coagulant-treated FFT upon resuspension \\
\hline Resuspension Scenario 3 & Coagulant-treated + Untreated & Untreated & $\begin{array}{l}\text { Potential interactions between treated and untreated } \\
\text { FFT upon resuspension }\end{array}$ \\
\hline
\end{tabular}


Turbidity and $\mathrm{pH}$ measurements were taken regularly (every three to seven days) after resuspension. The particle size distribution and zeta potential of coagulant-treated FFT particles were measured immediately (within $5 \mathrm{~min}$ ) after resuspension. EC and the same selected ions were analyzed immediately after resuspension and 22 days after resuspension. Scanning electron microscope (SEM) images were obtained for untreated FFT particles, FFT particles treated with $54 \mathrm{mg} / \mathrm{L}$ of $\mathrm{Ca}$, and FFT particles treated with $1.7 \mathrm{mg} / \mathrm{L}$ of $\mathrm{Al}$ before and after resuspension. SEM in this work was conducted at the University of Alberta Nanofab Research Facility with a Zeiss EVO MA10 (Jena, Germany). For SEM analysis, FFT particles were collected on the filter paper $(0.1 \mu \mathrm{m}$ pore size $)$ of EMD Millipore ${ }^{\mathrm{TM}}$ Stericup $^{\mathrm{TM}}$ sterile vacuum filter units (Fisher Scientific).

\section{Scenario 3: Resuspension of Both Untreated and Coagulant-Treated FFT Particles in Untreated BML Surface Water}

Coagulant-treated FFT particles were obtained in the same manner as described above and mixed with the same amount of untreated FFT particles (0.1-0.15 g (wet weight)). The mixture of coagulant-treated and untreated FFT particles was resuspended in untreated BML surface water $(450 \mathrm{~mL})$ on a shaker for $3 \mathrm{~h}$ at $160 \mathrm{rpm}$ and allowed to settle for 20-30 days. Each treatment was set up in duplicate. Turbidity, $\mathrm{pH}$, particle size distribution, zeta potential, EC, and selected ions were analyzed in the same manner as previously described.

\section{Statistical Analysis}

The two-sample t-test and the ANOVA test were performed to indicate the statistical significance (at $\alpha=0.05$ or $\alpha=0.1$ ) of the differences in turbidity, particle size distribution, and zeta potential among $\mathrm{Al}$ and $\mathrm{Ca}$ treatments in the above experiments. For differences in the concentrations of $\mathrm{Ca}$ and $\mathrm{Al}$ within each treatment, the paired $t$ test was used. The complete set of data from the statistical analysis is available in Supplementary Table 1.

\section{Results}

\section{Initial Material Characterization}

Most of the FFT particles are clay-sized $(<2 \mu \mathrm{m})$ and $50 \%$ of the particles have a diameter $<1.1 \pm 0.1 \mu \mathrm{m}$, based on sedimentation analysis. This agrees with previous mineralogical analysis of BML FFT, which found that the particles were predominately quartz and clay minerals (commonly kaolinite, illite, and chlorite) (Dompierre et al. 2016). The geochemical properties of BML surface water are presented in Table 2. BML surface water is alkaline with a high buffering capacity $\left(623.7 \pm 12.5 \mathrm{mg} / \mathrm{L}\right.$ as $\left.\mathrm{CaCO}_{3}\right)$, which is consistent with the findings of previous work (White and Liber 2018). Sodium is the most abundant cation at a concentration of $550.2 \pm 22.2 \mathrm{mg} / \mathrm{L}$, and chloride and sulfate are the predominant anion species at concentrations of $403.1 \pm 2.5 \mathrm{mg} / \mathrm{L}$ and $174.0 \pm 0.4 \mathrm{mg} / \mathrm{L}$, respectively. These concentrations are slightly less than previously reported for OSPW in oil sands tailings ponds (Small et al. 2012; Wang et al. 2015). This is due to dilution by fresh lake water, which is intermittently pumped into BML. The concentrations of DOC and AEOs are $51.1 \pm 0.1 \mathrm{mg} / \mathrm{L}$ and $63.9 \pm 0.1 \mathrm{mg} / \mathrm{L}$, respectively. As noted in Small et al. (2012), AEOs include the classical naphthenic acids (NAs), oxy NAs, and N- and S-containing organics. The acute toxicity of OSPW has been attributed to the extractable organic acid fraction, which includes NAs (Garcia-Garcia et al. 2011; Morandi et al. 2015). The turbidity in BML surface water is $20.5 \pm 1.0$ NTU. BML surface water samples were collected in August when the lowest turbidity is usually observed during the open water season (Lawrence et al. 2016). The persistent turbidity can be due to a low proportion of multivalent cations, a high $\mathrm{pH}$, and resuspension of fine particles from the underlying FFT layer.

\section{Effects of Calcium and Aluminum on Turbidity Reduction in BML Surface Water}

The bottle coagulation tests were set up to investigate the effectiveness of $\mathrm{Ca}$ and $\mathrm{Al}$ in reducing turbidity in BML surface water. The results are presented in Fig. 1 and indicate that both $\mathrm{Ca}$ and $\mathrm{Al}$ can enhance the coagulation process in

Table 2 Geochemical properties of BML surface water

\begin{tabular}{ll}
\hline Parameter & BML surface water \\
\hline $\mathrm{pH}$ & $8.3 \pm 0.1$ \\
Conductivity (mS/cm) & $2.84 \pm 0.1$ \\
Turbidity (NTU) & $20.5 \pm 1.0$ \\
Alkalinity (mg/L as $\left.\mathrm{CaCO}_{3}\right)$ & $623.7 \pm 12.5$ \\
$\mathrm{Cl}^{-}(\mathrm{mg} / \mathrm{L})$ & $403.1 \pm 2.5$ \\
$\mathrm{SO}_{4}{ }^{2-}(\mathrm{mg} / \mathrm{L})$ & $174.0 \pm 0.4$ \\
$\mathrm{NO}_{3}{ }^{-}(\mathrm{mg} / \mathrm{L})$ & $1.8 \pm 0.3$ \\
$\mathrm{Na}^{+}(\mathrm{mg} / \mathrm{L})$ & $550.2 \pm 22.2$ \\
$\mathrm{~K}^{+}(\mathrm{mg} / \mathrm{L})$ & $12.2 \pm 2.3$ \\
$\mathrm{Mg}^{2+}(\mathrm{mg} / \mathrm{L})$ & $11.1 \pm 0.6$ \\
$\mathrm{Ca}^{2+}(\mathrm{mg} / \mathrm{L})$ & $23.7 \pm 1.0$ \\
$\mathrm{Al}^{3+}(\mathrm{mg} / \mathrm{L})$ & $0.11 \pm 0.04$ \\
$\mathrm{Fe}^{3+}(\mathrm{mg} / \mathrm{L})$ & $\mathrm{BDL}$ \\
$\mathrm{DOC}^{(\mathrm{mg} / \mathrm{L})}$ & $51.1 \pm 0.1$ \\
$\mathrm{AEO}^{(\mathrm{mg} / \mathrm{L})}$ & $63.9 \pm 0.1$
\end{tabular}




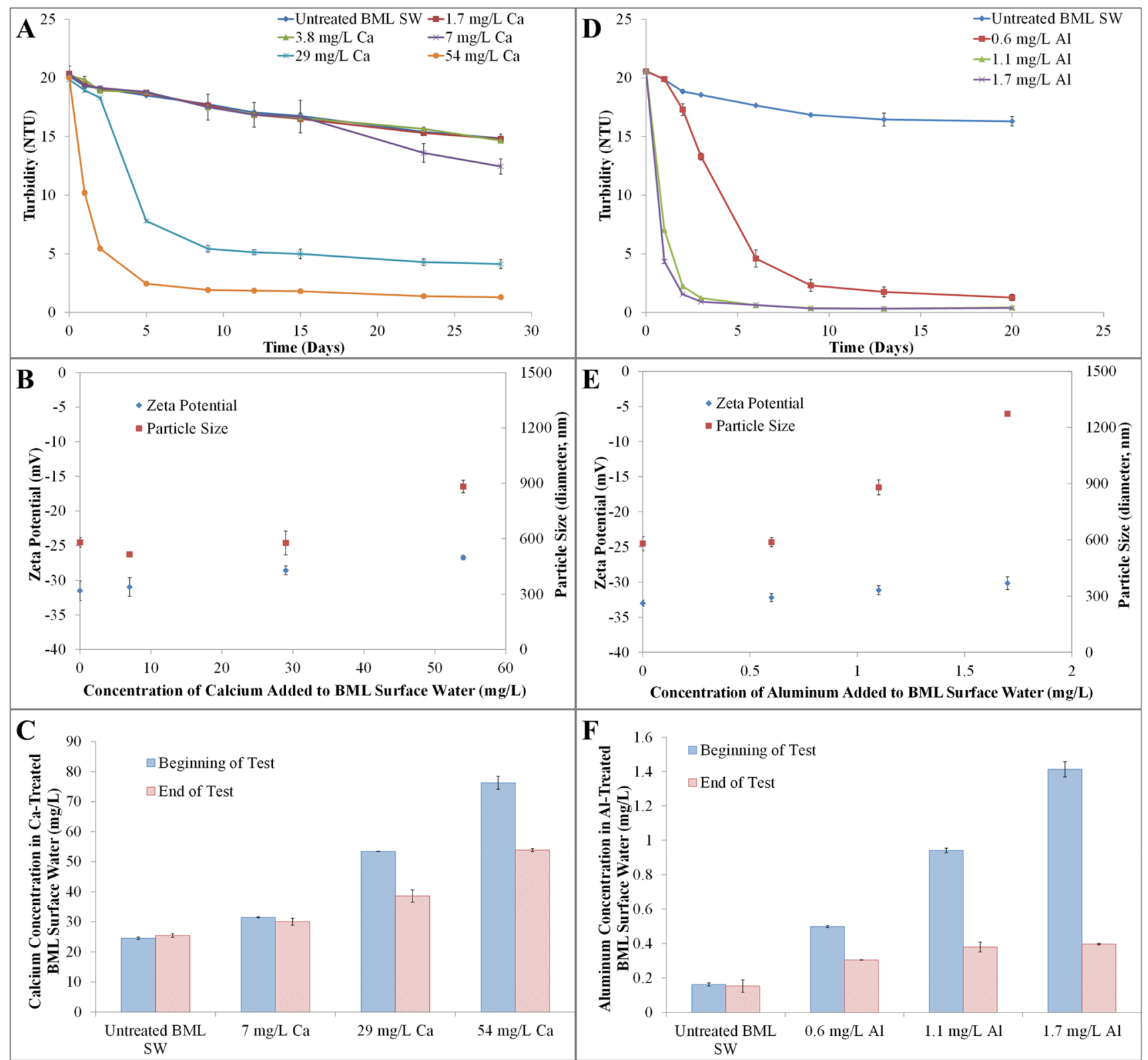

Fig. 1 Changes in Turbidity, Zeta Potential, Particle Size, and Concentrations of Calcium and Aluminum during Bottle Coagulation Tests. A-C correspond to calcium treatment; D-F correspond to

BML surface water. The $54 \mathrm{mg} / \mathrm{L} \mathrm{Ca}$ treatment decreased the turbidity from 20.0 NTU to 5.4 NTU on Day 2 and further down to $1.3 \mathrm{NTU}$ at Day 28 (Fig. 1A). The $1.7 \mathrm{mg} / \mathrm{L}$ $\mathrm{Al}$ treatment caused the turbidity to drop from 20.5 NTU to 1.6 NTU at Day 2 and further down to 0.39 NTU at Day 20 (Fig. 1D), whereas the same mass concentration or equivalent concentration of $\mathrm{Ca}$ in BML surface water did not result in significant turbidity reductions compared to untreated BML surface water (Fig. 1A). There was no obvious difference in turbidity reduction with $\mathrm{Al}$ treatments of $1.1 \mathrm{mg} / \mathrm{L}$ or $1.7 \mathrm{mg} / \mathrm{L}$. With $0.6 \mathrm{mg} / \mathrm{L}$ of $\mathrm{Al}$, a rapid drop in turbidity was aluminum treatment. Results are averaged from duplicated trials and error bars represent the upper and lower limits of the duplicate measurements. (Surface water abbreviated SW)

observed in the first six days (from 20.6 NTU to 4.6 NTU) and the final turbidity reached $1.3 \mathrm{NTU}$ at the end of the coagulation test (Day 20) (Fig. 1D). This suggests that $\mathrm{Al}$ is more effective than $\mathrm{Ca}$ in enhancing the coagulation process in BML surface water $(p=0.0001$ at $\alpha=0.05$ when comparing turbidity at the end of the tests for the same equivalent concentrations).

Several studies have compared the effectiveness of $\mathrm{Ca}$ and $\mathrm{Al}$ in coagulating clay particles. Teot and Daniels (1969) plotted counterion valence vs. the logarithm of the concentrations of $\mathrm{Na}, \mathrm{Ca}$, and $\mathrm{Al}$ required to flocculate 
monodisperse latex particles and found that higher valent cations required lower concentrations to achieve optimum coagulation. Matthews et al. (2002) showed that Al was more effective in inducing coagulation and segregation of oil sands tailings than $\mathrm{Ca}$ at a Syncrude operation site during the composite tailings process. Trefalt et al. (2013) found an empirical relationship in which the critical coagulation concentration scales as $\mathrm{z}^{-\mathrm{n}}$, where $\mathrm{z}$ is the valence of the counterion and depends on the particle surface charge density. The results of this study are consistent with the findings from previous research, in that $\mathrm{Al}$ required a lower dosage than $\mathrm{Ca}$ to reduce the turbidity to $<1.5 \mathrm{NTU}$ in BML surface water.

The zeta potential increased from $-31.5 \mathrm{mV}$ to $-26.7 \mathrm{mV}$ with increasing concentrations of $\mathrm{Ca}$ added to BML surface water, and the particle size increased from 579.9 to 882.5 $\mathrm{nm}$ (Fig. 1B). However, the difference in zeta potential for Ca treatment was not statistically significant at a $95 \%$ confidence level ( $\mathrm{p}=0.0872)$, possibly due to the small sample size $(n=2)$ for each treatment. A smaller increase in zeta potential (from $-33 \mathrm{mV}$ to $-30.2 \mathrm{mV}$ ) and a greater increase in particle size (from $579.9 \mathrm{~nm}$ to $1273.5 \mathrm{~nm}$ ) were observed for the $\mathrm{Al}$ treatments (Fig. 1E). Adding $\mathrm{Ca}$ or $\mathrm{Al}$ to BML surface water changed both the $\mathrm{pH}$ (within the range of 8-8.6) and EC (within the range of $2.8 \mathrm{mS} / \mathrm{cm}-3.1 \mathrm{mS} /$ $\mathrm{cm}$ ) of the suspension (Supplementary Fig. S-1, Supplementary Fig. S-2) though Ca addition had a greater impact on $\mathrm{pH}$ than $\mathrm{Al}$ addition. Alkalinity also decreased slightly with increasing concentrations of $\mathrm{Ca}$ or $\mathrm{Al}$ (Supplementary Fig. S-3). These $\mathrm{pH}$ and EC changes may theoretically affect the zeta potential and particle size. However, without $\mathrm{Ca}$ or $\mathrm{Al}$, zeta potential and particle size did not vary significantly over the measured $\mathrm{pH}$ ranges of 8-8.7 and EC ranges of 2.8-3.4 mS/cm (Supplementary Fig. S-4. Thus, it can be concluded that the changes in zeta potential and particle size should be predominantly due to the interactions between the suspended particles in BML surface water and the cations added. The particles treated with $54 \mathrm{mg} / \mathrm{L}$ of Ca had a less-negative zeta potential, which generally indicates a higher tendency to coagulate, than particles treated with $1.7 \mathrm{mg} / \mathrm{L}$ of Al. However, particles treated with $1.7 \mathrm{mg} / \mathrm{L}$ of $\mathrm{Al}$ were much larger than particles treated with $54 \mathrm{mg} / \mathrm{L}$ of $\mathrm{Ca}$, and a faster coagulation process was observed in $\mathrm{Al}-$ treated BML surface water. This indicates that $\mathrm{Ca}$ and $\mathrm{Al}$ interacted differently with the suspended particles in BML surface water, possibly because $\mathrm{Ca}$ neutralizes the negative surface charge of the suspended particles to enhance the coagulation (Appelo and Postma 2005; Black et al. 1965; McFarlane et al. 2006), whereas $\mathrm{Al}$ forms $\mathrm{Al}(\mathrm{OH})_{3}$ precipitates at the $\mathrm{pH}$ of BML surface water $(\mathrm{pH} 8.3)$ to entrap and sweep the suspended particles (Dentel and Gossett 1988; Driscoll and Schecher 1990; May et al. 1979). However, according to the Al solubility curve (Dentel and Gossett 1988), the predominant form of Al species should be $\mathrm{Al}(\mathrm{OH})_{4}{ }^{-}$, instead of $\mathrm{Al}(\mathrm{OH})_{3}$, in $\mathrm{BML}(\mathrm{pH} 8.3)$ at the $\mathrm{Al}$ concentrations tested (Supplementary Fig. S-5). This might suggest that the presence of $\mathrm{Al}(\mathrm{OH})_{3}$, even at low concentrations, can be effective in coagulating and flocculating the suspended particles in BML. It is also possible that the $\mathrm{Al}$ solubility curve in BML surface water, which is a high-salt and alkaline environment, could be slightly different from the one obtained by Dentel and Gossett (1988). Furthermore, other mechanisms such as adsorption of polymeric metal hydroxides might also be involved in FFT particle settling. Further experiments and geochemical modeling need to be conducted to verify these mechanisms and elucidate the Al speciation in BML surface water. Concentrations of major cations and anions were measured to monitor the changes in water chemistry during the coagulation process. Calcium and $\mathrm{Al}$ concentrations decreased over time when the water was treated with $\mathrm{Ca}$ (Fig. 1C) and $\mathrm{Al}$ (Fig. 1F), confirming that these multivalent cations were involved in the respective coagulation processes. Profiles of other ions are presented as supplementary material.

\section{Scenario 1: Resuspension of Untreated FFT Particles in Coagulant-Treated BML Surface Water}

By the end of the bottle coagulation tests, the remaining concentrations of $\mathrm{Ca}$ and $\mathrm{Al}$ in coagulant-treated BML surface water were greater than those in untreated BML surface water (Fig. 1C, F). It was hypothesized that the remaining $\mathrm{Ca}$ and $\mathrm{Al}$ in coagulant-treated BML surface water could still enhance the coagulation and settling of fine particles resuspended during lake turnover. In BML, the resuspended particles consist of both fine particles that were previously coagulant-treated and settled and untreated FFT particles from the underlying FFT. To simplify the system, resuspension experiments were conducted by resuspending untreated FFT particles in coagulant-treated BML surface water. After resuspension, the trends in turbidity reduction and zeta potential were like those observed in the bottle coagulation tests (Fig. 2A, D). Higher concentrations of $\mathrm{Ca}$ and $\mathrm{Al}$ in BML surface water resulted in faster turbidity reduction rates for both treatments. This indicates that treatment of BML with $\mathrm{Ca}$ or $\mathrm{Al}$ could be effective in mitigating subsequent lake turnover-induced turbidity events. Additional water chemistry data for Resuspension Scenario 1 (additional cation concentrations, $\mathrm{pH}$, and $\mathrm{EC}$ ) is available in Supplementary Figs. S-6 to S-8.

The concentrations of $\mathrm{Ca}$ and $\mathrm{Al}$ remaining in BML surface water decreased by $2-6 \mathrm{mg} / \mathrm{L}$ (statistically significant at $\alpha=0.05$ ) and $0.1-0.15 \mathrm{mg} / \mathrm{L}$ (statistically significant at $\alpha=0.1$ ), respectively, during each of two resuspensions, for the corresponding treatments with $\mathrm{Ca}$ and $\mathrm{Al}$ (Fig. 2C, F). The sizes of untreated FFT particles also increased with increasing concentrations of the coagulants that 


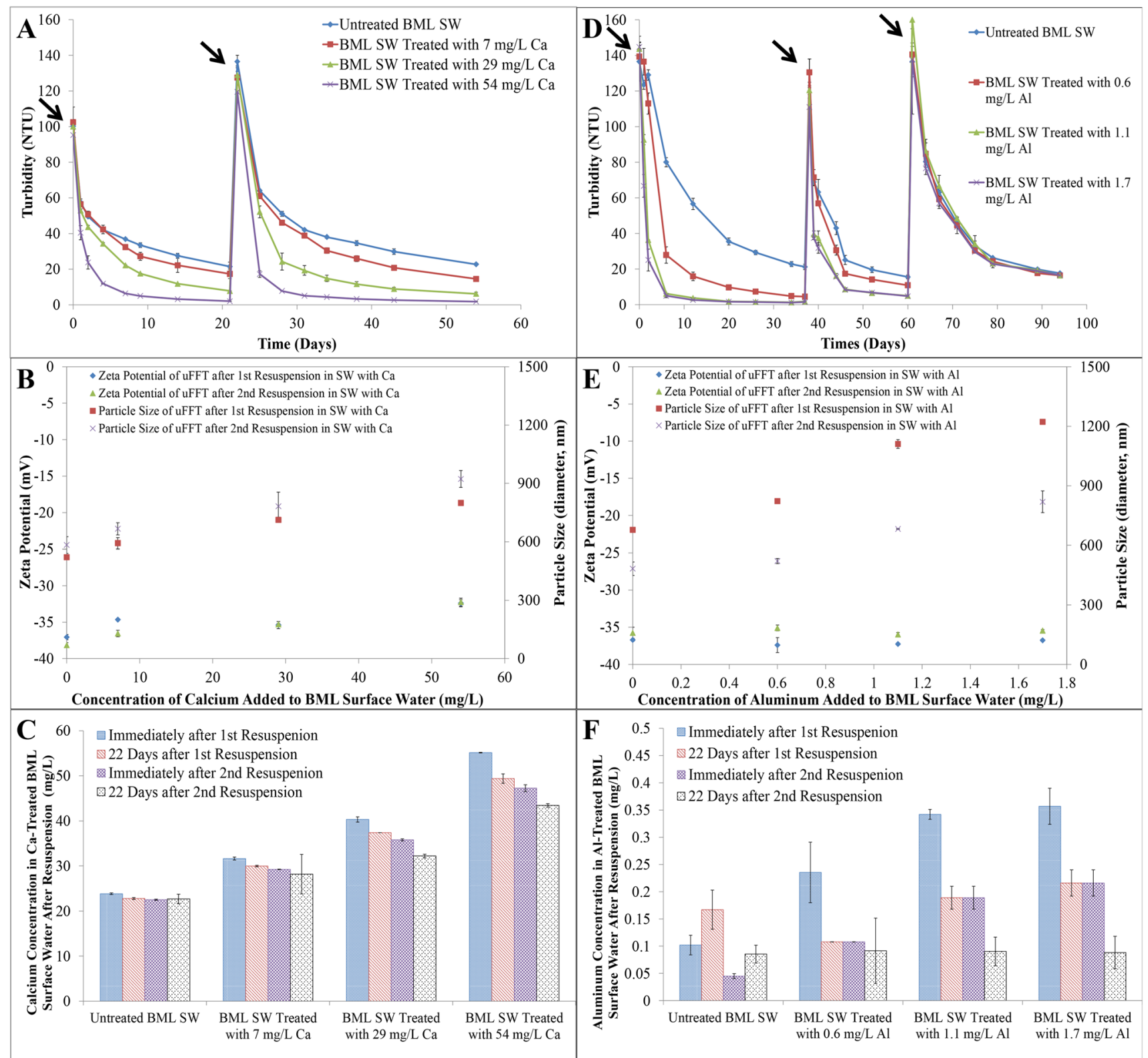

Fig. 2 Changes in Turbidity, Zeta Potential, Particle Size, and Concentrations of Calcium and Aluminum in Coagulant-treated BML Surface Water After Resuspension of Untreated FFT Particles. A-C correspond to calcium treatment; D-F correspond to aluminum treatment. Black arrows indicate the resuspensions of untreated FFT par-

were previously added to BML surface water (Fig. 2B, E). These observations indicate that the remaining $\mathrm{Ca}$ and $\mathrm{Al}$ in coagulant-treated BML surface water were involved in the coagulation of the introduced untreated FFT particles. After two resuspensions, the concentration of $\mathrm{Ca}$ in $\mathrm{Ca}$ treated BML water was still significantly higher than that in untreated BML surface water. It is reasonable to speculate that residual $\mathrm{Ca}$ ions in the $\mathrm{Ca}$-treated $\mathrm{BML}$ surface water can enhance the coagulation of the resuspended untreated ticles in coagulant-treated BML surface water. Results are averaged from duplicated trials and error bars represent the upper and lower limits of the duplicate measurements. (Surface water abbreviated SW; Untreated FFT abbreviated to uFFT)

FFT particles until the ions are consumed down to the background level (23-24 mg/L). However, after two resuspensions, the $\mathrm{Al}$ concentration in $\mathrm{Al}$-treated BML surface water had decreased to the background level (Fig. 2 F). It can be inferred that Al-treated BML surface water had lost its ability to coagulate untreated FFT particles after two resuspensions. This was confirmed by the statistically indifferent turbidity values among all $\mathrm{Al}$ treatments at the end of the third resuspension experiment (Fig. 2D, $p=0.7106$ at $\alpha=0.05$ ). 
Thus, the residual $\mathrm{Ca}$ or $\mathrm{Al}$ ions in Ca-treated and $\mathrm{Al}-$ treated BML surface water can still enhance the settling of the resuspended particles. However, this effect is likely to be temporary, since each resuspension and the subsequent particle settling would consume some of the $\mathrm{Ca}$ or $\mathrm{Al}$ ions in the coagulant-treated BML surface water. Once the residual $\mathrm{Ca}$ or $\mathrm{Al}$ ions are consumed, coagulant-treated BML surface water will be chemically similar to untreated BML surface water. At this point, the coagulation of the resuspended particles will no longer be enhanced in the coagulant-treated BML surface water.

\section{Scenario 2: Resuspension of Coagulant-Treated FFT Particles in Untreated BML Surface Water}

Not only was the water chemistry altered with the addition of $\mathrm{Ca}$ and $\mathrm{Al}$ to BML surface water, but the properties of the suspended particles in BML surface water were also changed during the coagulation process. Several studies (Holthoff et al. 1996; Lee et al. 2012; Tombacz et al. 1999) have indicated that the effective particle size increases during the coagulation process as a function of coagulant dosage, which was also demonstrated in this research. As a result, the coagulated (treated) particles should be more likely to resettle upon resuspension compared to untreated FFT particles. This hypothesis was investigated by resuspending coagulant-treated FFT particles in untreated BML surface water.

After resuspension, differences were seen in the turbidity reduction between $\mathrm{Ca}$ and $\mathrm{Al}$ treatments. The initial turbidity measurements were 102,114, 138, and 161 NTU after resuspension of FFT particles treated with $0,7,29$, and $54 \mathrm{mg} / \mathrm{L}$ of $\mathrm{Ca}$, respectively (Fig. 3A). In contrast to Ca treatment, similar initial turbidity values were found for all three Al treatment concentrations. Initial turbidity measurements ranged from $118 \mathrm{NTU}$ to $125 \mathrm{NTU}$ after resuspension of FFT particles that had been treated with $0.6 \mathrm{mg} / \mathrm{L}, 1.1 \mathrm{mg} / \mathrm{L}$, or $1.7 \mathrm{mg} / \mathrm{L}$ of $\mathrm{Al}$ (Fig. 3D). Ca-treated and Al-treated FFT particles were created by adding various concentrations of the respective cations to suspensions containing the same mass of untreated FFT particles. A higher concentration of $\mathrm{Ca}$ in the suspension created more Ca-treated and settled FFT particles and thus a higher initial turbidity value was observed after resuspension, whereas similar amounts of Altreated and settled FFT particles were obtained regardless of the concentrations of $\mathrm{Al}$ in the suspensions. This interesting finding could be further evidence that the coagulation processes of $\mathrm{Ca}$ and $\mathrm{Al}$ are different in BML surface water. Additional water chemistry data for Resuspension Scenario 2 (additional cation concentrations, $\mathrm{pH}$, and $\mathrm{EC}$ ) is available in Supplementary Figs. S-9 to S-11.

There were no significant differences in zeta potential and particle size between Ca-treated and untreated FFT particles (Fig. 3B, p=0.9854 at $\alpha=0.05$ ). This indicates that the properties of Ca-treated FFT particles should be like those of untreated FFT particles after resuspension. For this reason, similar final turbidity values were observed among all $\mathrm{Ca}$ treatments 22 days after resuspension (Fig. $3 \mathrm{~A}$, $p=0.6896$ at $\alpha=0.05$ ). On the other hand, the particle size of Al-treated FFT particles was greater than that of untreated FFT particles by $100-700 \mathrm{~nm}$ (Fig. 3E, $\mathrm{p}=0.0041$ at $\alpha=0.05$ ). FFT particles previously treated with higher concentrations of $\mathrm{Al}$ settled faster after resuspension, resulting in lower final turbidities in BML surface water (Fig. 3D, $p=0.0007$ at $\alpha=0.05$ ). The settling rate of Al-treated FFT particles was positively correlated with the size of the particles. There were no significant changes in water chemistry after resuspension of Ca-treated or Al-treated FFT particles in untreated BML surface water (Fig. 3C, F, statistically insignificant at $\alpha=0.05$ ), indicating that $\mathrm{Ca}$-induced or Alinduced coagulation did not take place during this resuspension experiment. The different turbidity reduction patterns between $\mathrm{Ca}$ and $\mathrm{Al}$ treatments after resuspension should be solely due to the different properties of Ca-treated and Altreated FFT particles.

SEM analysis was performed to further examine the morphological change of Ca-treated and Al-treated FFT particles during resuspension in fresh BML surface water. Before resuspension, FFT particles treated with $\mathrm{Ca}$ and $\mathrm{Al}$ were bound together to form sheet-like structures, whereas separate clay particles were observed for untreated FFT particles (Supplementary Fig. S-12). The sheet-like structure of Catreated FFT particles was not as smooth as that of Al-treated FFT particles. There was no significant change in the morphology of untreated FFT particles or Al-treated particles during resuspension. The sheet-like structure for Al-treated FFT particles was still intact after resuspension (Supplementary Fig. S-12). However, after resuspension, Ca-treated FFT particles became morphologically like untreated FFT particles, and the sheet-like structure likely broke apart (Supplementary Fig. S-12). The results of SEM analysis support the previously discussed observations made regarding the zeta potential, particle size, and turbidity reduction patterns. It is reasonable to speculate that $\mathrm{Al}$ had a stronger interaction with the suspended particles in BML surface water than ca. The applied shear stress during resuspension, which was not covered in this study, is an important parameter to consider as it affects the break-up of the sheet-like structures of Ca-treated and Al-treated particles. Further experiments should be designed to investigate the shear stresses required to break apart the structures of Ca-treated and Al-treated particles, and how these shear stresses are relevant to field conditions in BML.

In summary, after Ca-treated FFT particles were resuspended in untreated BML surface water, they became like untreated FFT particles in terms of particle surface charge 


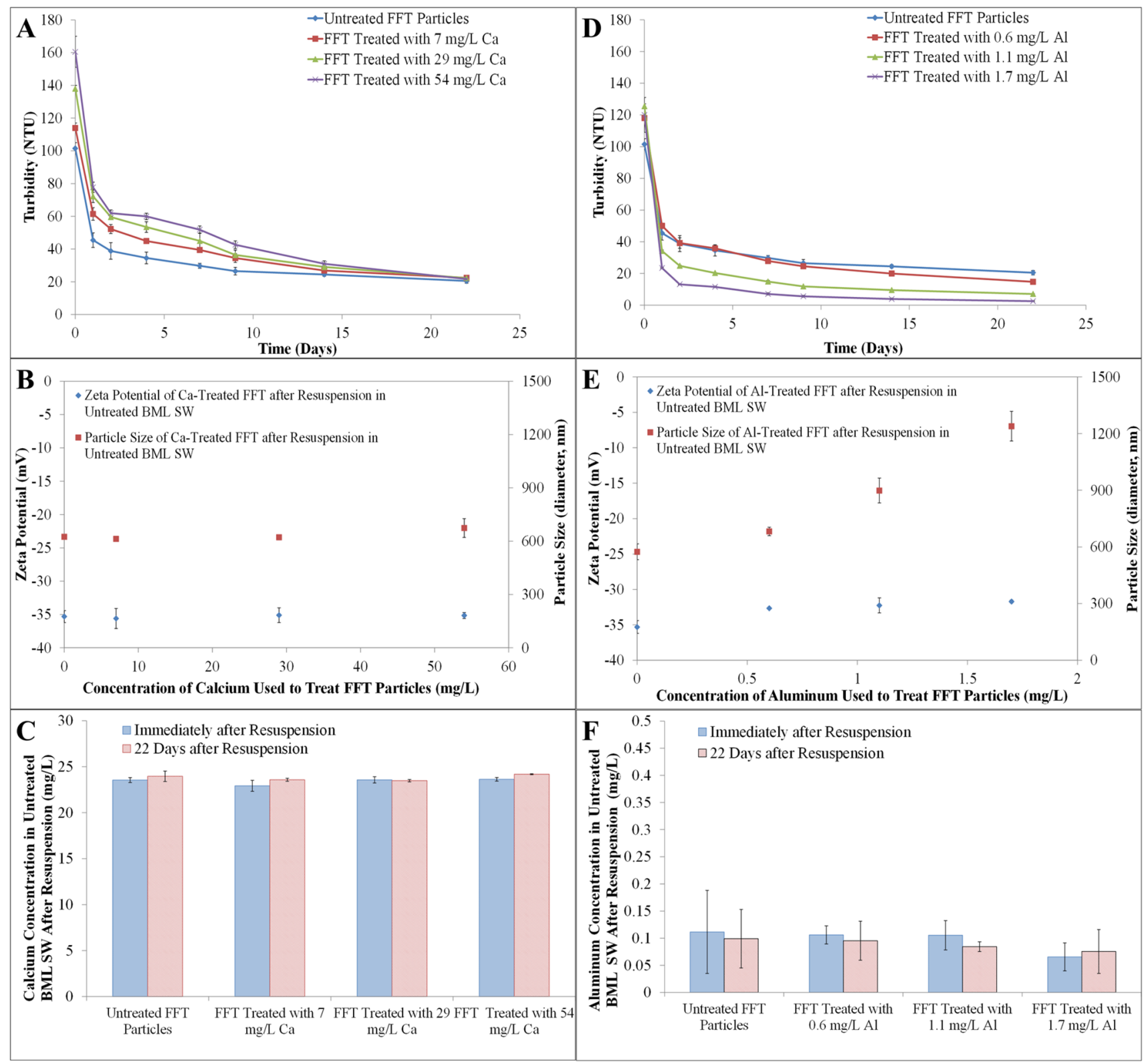

Fig. 3 Changes in Turbidity, Zeta Potential, Particle Size, and Concentrations of Calcium and Aluminum in Untreated BML Surface Water After Resuspension of Coagulant-treated FFT Particles. A-C correspond to calcium treatment; D-F correspond to aluminum treatment. Results are averaged from duplicated trials and error bars represent the upper and lower limits of the duplicate measurements. (Surface water abbreviated SW)

\section{Scenario 3: Resuspension of Both Untreated and Coagulant-Treated FFT Particles in Untreated BML Surface Water}

This resuspension experiment attempted to simulate the condition where both untreated FFT particles and coagulant-treated FFT particles were resuspended in BML 
surface water after the residual coagulant had been consumed. It should be noted that it is impractical to quantify the amount of each kind of particles resuspended in BML. Therefore, this experiment assumed equal amounts of untreated and coagulant-treated FFT particles were resuspended. As shown in Fig. 4, the turbidity reduction patterns and changes in zeta potential, particle size, and cation concentrations were like those observed above. The particle size of the mixtures containing untreated and Altreated FFT particles increased when the Al-treated FFT particles had been treated with higher concentrations of $\mathrm{Al}$ (Fig. 4E). The data suggests that there could be some interactions between the resuspended untreated and Altreated FFT particles. The resulting large mixture particles could settle rapidly due to their weight. This effect was not observed in the mixture containing untreated and $\mathrm{Ca}-$ treated FFT particles, possibly because Ca-treated FFT particles became like untreated FFT particles in terms of particle size and morphology. Additional water chemistry data for Resuspension Scenario 3 (additional cation
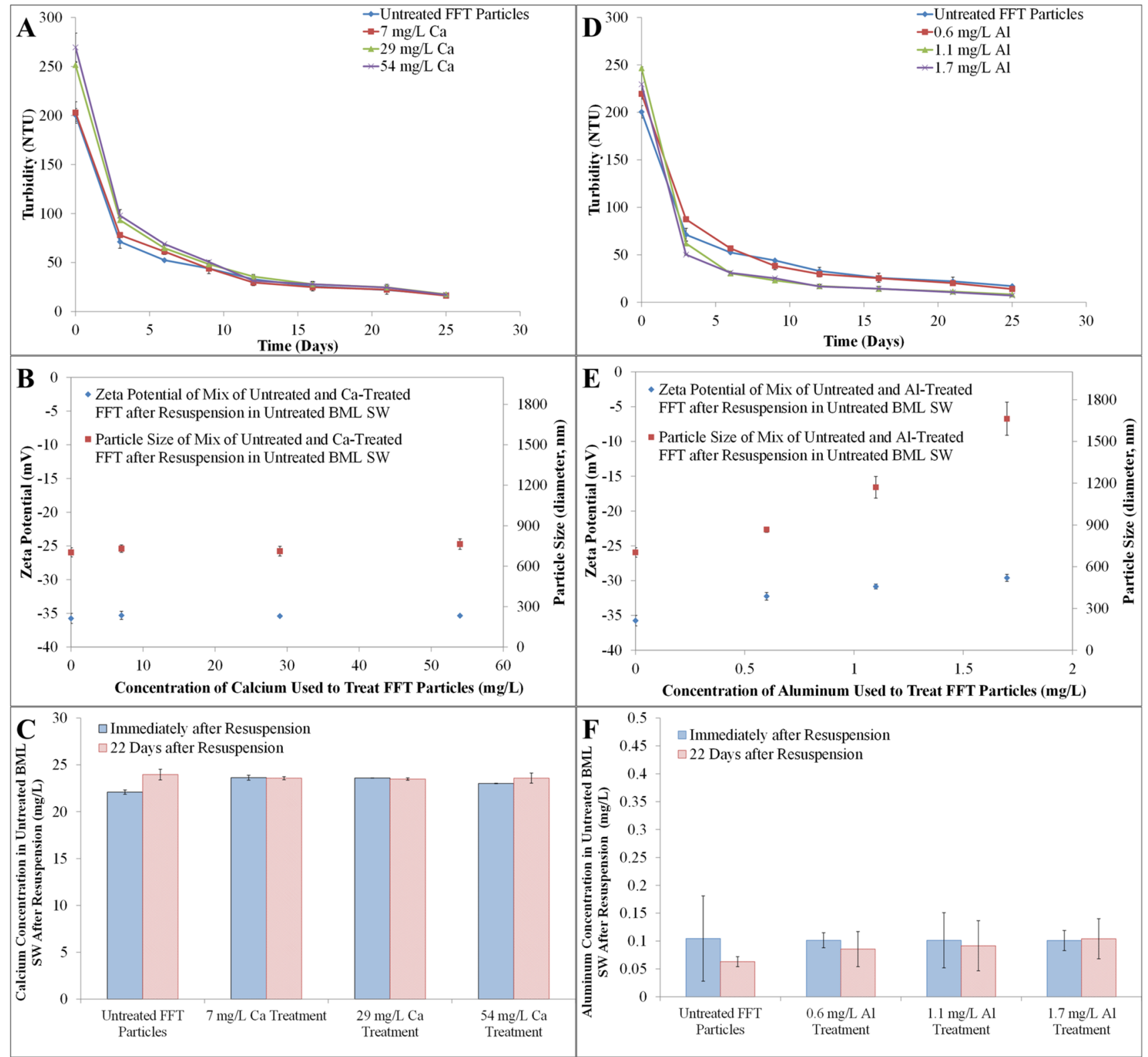

Fig. 4 Changes in Turbidity, Zeta Potential, Particle Size, and Concentrations of Calcium and Aluminum in Untreated BML Surface Water After Resuspension of Mixtures Containing both Untreated and Coagulant-treated FFT Particles. A-C correspond to calcium treatment; D-F correspond to aluminum treatment. Results are averaged from duplicated trials and error bars represent the upper and lower limits of the duplicate measurements. (Surface water abbreviated SW) 
concentrations, $\mathrm{pH}$, and EC) is available in Supplementary Figs. S-13 to S-15.

Upon resuspension of both untreated and Al-treated particles, untreated FFT particles could collide with Al-treated FFT particles through Brownian motion, fluid shear, and/ or differential sedimentation, and these collisions might enhance the settling of both types of particles. This process is similar to the enhanced coagulation of fine particles by adding appropriate coarse particles, which has been observed in mineral floatation systems and termed "slime coating" (Song et al. 2006). The mechanism of the coarse particle effect was attributed to the increased aggregation rate because the collision rate between coarse particles and fine particles is much greater than that between fine particles themselves (Song and Lopez-Valdivieso 2002). Further experiments should be conducted to verify this hypothesis and gain a comprehensive understanding of the interactions between untreated and Al-treated FFT particles in BML surface water. The data indicate that $\mathrm{Al}$ treatment in BML could have a long-term effect, mitigating turbidity issues in BML even after initial dosing and turbidity removal. The longterm effect of $\mathrm{Al}$ may be due to the self-weight resettling of the resuspended previously-formed, large Al-treated particles and the interactions between resuspended particles, as long as the shear stress during resuspension (e.g. lake turnover) is not strong enough to break apart Al-treated particles.

It should be noted that the $\mathrm{Al}$ doses used in this work produced transiently higher concentrations of $\mathrm{Al}$ than background concentration in the BML surface water $(0.11 \pm 0.04 \mathrm{mg} / \mathrm{L})$ after initial dosing and coagulation during the bottle coagulation tests (see Supplementary Fig. S-3E). However, after subsequent resuspension tests, the residual concentrations of dissolved $\mathrm{Al}$ after coagulation and particle settling occurred were similar to or less than the background concentration in BML surface water (see Supplementary Figs. S-6E, S-9E, and S-13E). Thus, with the doses tested in this work, no increase in the residual concentrations of $\mathrm{Al}$ in the BML surface water occurred.

\section{Conclusions}

Bottle coagulation tests suggest that $\mathrm{Al}$ is a more effective coagulant than $\mathrm{Ca}$ to mitigate the initial turbidity issue in BML surface water. Aluminum enhanced particle settling in BML surface water at relatively low concentrations, whereas the same mass concentration or equivalent concentration of Ca did not result in significant turbidity reductions (Fig. 1). Following the initial coagulant treatment and the subsequent resuspension events, the residual and unreacted coagulant in BML surface water could still enhance the coagulation of the resuspended particles before it was consumed (Fig. 2). Furthermore, FFT particles treated with Al maintained their size and demonstrated possible interactions with untreated particles after resuspension in BML surface water, resulting in a faster resettling rate than Ca-treated particles (Figs. 3 and 4 ). These results suggest that $\mathrm{Al}$ is a promising coagulant for reducing additional turbidity introduced during lake turnovers, or through other mechanisms such as erosion, in the years after initial turbidity removal.

In parallel with this study, Syncrude Canada Ltd. added alum to BML, and significant turbidity reduction was observed following the initial alum addition. Rigorous monitoring is being conducted to verify if alum has any prolonged effect on turbidity mitigation in BML following the initial dosage and to evaluate the long-term geochemical development of BML. The actual BML system is much more complex than the laboratory system in this study. Several processes could affect the turbidity in BML, and the field data obtained to date is insufficient to make any conclusions about the mixing mechanisms of suspended solids in BML surface water (Lawrence et al. 2016). This study specifically targeted the increase in turbidity caused by the resuspension of fine particles at the FFT-surface water interface. Other turbidity sources such as shoreline erosion should also be considered. Moreover, the coagulation mechanisms of $\mathrm{Ca}$ and $\mathrm{Al}$ need to be further evaluated to comprehensively understand the differences in turbidity reduction rates, zeta potentials, and the resuspended particle properties between $\mathrm{Ca}$ and $\mathrm{Al}$ treatments. Mineralogical analysis should be conducted to characterize the mineralogy of untreated, coagulant-treated, and re-suspended FFT particles in BML. In addition, geochemical modeling of BML surface water and FFT porewater will be necessary to reveal Al speciation following alum treatment, as well as other precipitation and carbonate-mineral dissolution processes that may affect particle settling and resuspension in BML.

Supplementary Information The online version contains supplementary material available at https://doi.org/10.1007/s10230-021-00808-9.

Acknowledgements This work was supported by an NSERC Collaborative Research and Development Grant (CRDPJ 476652-14) and Syncrude Canada Ltd. The authors would like to thank Carla Wytrykush and Dallas Heisler at Syncrude Canada Ltd. for coordinating Base Mine Lake samples and for technical assistance throughout the project, and James He for assistance with experiment set-up. We also wish to thank the Natural Resources Analytical Laboratory at the University of Alberta for providing the cation analysis via ICP-OES.

Open Access This article is licensed under a Creative Commons Attribution 4.0 International License, which permits use, sharing, adaptation, distribution and reproduction in any medium or format, as long as you give appropriate credit to the original author(s) and the source, provide a link to the Creative Commons licence, and indicate if changes were made. The images or other third party material in this article are included in the article's Creative Commons licence, unless indicated otherwise in a credit line to the material. If material is not included in the article's Creative Commons licence and your intended use is not permitted by statutory regulation or exceeds the permitted use, you will 
need to obtain permission directly from the copyright holder. To view a copy of this licence, visit http://creativecommons.org/licenses/by/4.0/.

\section{References}

Abolfazlzadehdoshanbehbazari M, Birks SJ, Moncur MC, Ulrich AC (2013) Fate and transport of oil sand process-affected water into the underlying clay till: a field study. J Contam Hydrol 151:83-92

AER (Alberta Energy Regulator) (2019) State of fluid tailings management for mineable oil sands, 2018. Alberta Energy Regulator, Calgary

American Society for Testing Materials (ASTM) International (2017) Standard Test Method for Particle-size Distribution (Gradation) of Fine-grained Soils Using the Sedimentation (Hydrometer) Analysis (D7928-17). ASTM International, West Conshohocken, Pennsylvania

Appelo CAJ, Postma D (2005) Geochemistry, groundwater and pollution, 2nd edn. A.A. Balkema Publishers, Leiden

Black AP, Birkner FB, Morgan JJ (1965) Destabilization of dilute clay suspensions with labeled polymers. J Am Water Works Ass 57:1547-1560

Charette T, Castendyk D, Hrynshyn J, Kupper A, Mckenna G, Mooder B (2010) End Pit Lakes Guidance Document 2012. Cumulative Environmental Management Assoc, Fort McMurray, Alberta

Dentel SK, Gossett JM (1988) Mechanisms of coagulation with aluminum salts. J Am Water Works Ass 80:187-198

Dompierre KAA, Lindsay MBJ, Cruz-Hernández P, Halferdahl GM (2016) Initial geochemical characteristics of fluid fine tailings in an oil sands end pit lake. Sci Total Environ 556:196-206

Driscoll CT, Schecher WD (1990) The chemistry of aluminum in the environment. Environ Geochem Hlth 12:28-49

Garcia-Garcia E, Pun J, Perez-Estrada LA, Din MGE, Smith DW, Martin JW, Belosevic M (2011) Commercial naphthenic acids and the organic fraction of oil sands process water downregulate pro-inflammatory gene expression and macrophage antimicrobial responses. Toxicol Lett 203:62-73

Hardy WB (1900) A preliminary investigation of the conditions which determine the stability of irreversible hydrosols. J Phys Chem 4:235-253

Holthoff H, Egelhaaf SU, Borkovec M, Schurtenberger P, Sticher H (1996) Coagulation rate measurements of colloidal particles by simultaneous static and dynamic light scattering. Langmuir 12:5541-5549

Kasperski KL, Mikula RJ (2011) Waste streams of mined oil sands: characteristics and remediation. Elements 7:387-392

Lawrence GA, Tedford EW, Pieters R (2016) Suspended solids in an end pit lake: potential mixing mechanisms. Can J Civil Eng 43:211-217

Lee BJ, Schlautman MA, Toorman E, Fettweis M (2012) Competition between kaolinite flocculation and stabilization in divalent cation solutions dosed with anionic polyacrylamides. Water Res 46:5696-5706

Long J, Li H, Xu Z, Masliyah JH (2006) Role of colloidal interactions in oil sand tailings treatment. AICHE J 52:371-383

Mahdavi H, Prasad V, Liu Y, Ulrich AC (2015) In situ biodegradation of naphthenic acids in oil sands tailings pond water using indigenous algae-bacteria consortium. Bioresour Technol 187:97-105

Matthews JG, Shaw WH, MacKinnon MD, Cuddy RG (2002) Development of composite tailings technology at Syncrude. Int J Min Reclam Env 16:24-39
May HM, Helmke PA, Jackson ML (1979) Gibbsite solubility and thermodynamic properties of hydroxy-Aluminum ions in aqueoussolution at 25 C. Geochem Cosmochim Acta 43:861-868

McFarlane A, Bremmell K, Addai-Mensah J (2006) Improved dewatering behavior of clay minerals dispersions via interfacial chemistry and particle interactions optimization. J Colloid Interface Sci 293:116-127

Morandi GD, Wiseman SB, Pereira A, Mankidy R, Gault IGM, Martin JW, Giesy JP (2015) Effects-directed analysis of dissolved organic compounds in oil sands process-affected water. Environ Sci Technol 49:12395-12404

Schofield RK, Samson HR (1954) Flocculation of kaolinite due to the attraction of oppositely charged crystal faces. Discuss Faraday Soc 18:135-145

Schofield RK, Samson HR (1954) Flocculation of kaolinite due to the attraction of oppositely charged crystal faces. Discuss Faraday Soc 18: $135-145$

Schulze H (1882) Schwefelarsen in wässriger Lösung. J Prakt Chem 25:431

Song S, Lopez-Valdivieso A (2002) Parametric aspect of hydrophobic flocculation technology. Min Proc Ext Met Rev 23:101-127

Song S, Lopez-Valdivieso A, Hernandez-Campos DJ, Peng C, MonroyFernandez MG, Razo-Soto I (2006) Arsenic removal from higharsenic water by enhanced coagulation with ferric ions and coarse calcite. Water Res 40:364-372

Sutherland BR, Barrett KJ, Gingras MK (2015) Clay settling in fresh and salt water. Environ Fluid Mech 15:147-160

Sworska A, Laskowski JS, Cymerman G (2000) Flocculation of the Syncrude fine tailings Part I. Effect of $\mathrm{pH}$, polymer dosage and $\mathrm{Mg} 2+$ and $\mathrm{Ca} 2+$ cations. Int J Miner Process 60:143-152

Syncrude Canada Ltd (2019) Tailings management. https://www. syncrude.ca/environment/tailings-management/. Accessed 21 May 2019

Tedford E, Halferdahl G, Pieters R, Lawrence GA (2019) Temporal variations in turbidity in an oil sands pit lake. Environ Fluid Mech 19:457-473

Teot AS, Daniels SL (1969) Flocculation of negatively charged colloids by inorganic cations and anionic polyelectrolytes. Environ Sci Technol 3:825-829

Tombacz E, Filipcsei G, Szekeres M, Gingl Z (1999) Particle aggregation in complex aquatic systems. Colloid Surf 151:233-244

Tombacz E, Filipcsei G, Szekeres M, Gingl Z (1999) Particle aggregation in complex aquatic systems. Colloid Surf 151:233-244

Wang CJ, Alpatova A, McPhedran KN, El-Din MG (2015) Coagulation/flocculation process with polyaluminum chloride for the remediation of oil sands process-affected water: performance and mechanism study. J Environ Manag 160:254-262

White J, Stewart C, Wareham D, Wilson T (2011) Treatment of volcanic ash-contaminated surface waters through the optimisation of physical and chemical processes. GNS Sci Rep 2011/35:34

White KB, Liber K (2018) Early chemical and toxicological risk characterization of inorganic constituents in surface water from the Canadian oil sands first large-scale end pit lake. Chemosphere 211:745-757

Publisher's Note Springer Nature remains neutral with regard to jurisdictional claims in published maps and institutional affiliations. 